\title{
Spatio-temporal variability of fish assemblages in the Gambia Estuary (West Africa) observed by two vertical hydroacoustic methods: Moored and mobile sampling
}

\author{
Jean Guillard ${ }^{1,4, a}$, Jean-Jacques Albaret ${ }^{2}$, Monique Simier ${ }^{1}$, Ibrahima Sow ${ }^{3}$, Jean Raffray ${ }^{2}$ \\ and Luis Tito de Morais ${ }^{2}$ \\ IRD, Centre de Recherche Halieutique Méditerranéenne et Tropicale, BP 171, 34203 Sète Cedex, France \\ 2 IRD, Centre IRD de Dakar, UR070, BP 1386, Dakar, Sénégal \\ 3 CRODT, BP 2241, Dakar, Sénégal \\ 4 INRA, Station Hydrobiologie Lacustre, UMR CARRTEL, BP 511, 74203 Thonon les bains, France
}

Received 25 July 2003; Accepted 2 December 2003

\begin{abstract}
The Gambia Estuary is one of the last estuaries in West Africa not to have been affected by strong environmental changes and adverse human disturbances. In order to describe the spatio-temporal change in fish biomass in this estuary, and the seasonal changes in fish size classes, five research surveys have been conducted at characteristic periods in the river's water regime and meteorological seasons. The fish assemblages were sampled by two vertical echosounding protocols: mobile surveys (zigzag transects) in the estuary and moored stations. The two sampling methods produced a similar image of the fish assemblages in terms of the distribution of total biomass and target strength distributions. Large fish aggregations were detected in the most marine area at the end of the wet season, and fish biomass increased through the dry season in the upstream zone. Fish were smaller at the beginning of the wet season and they were always larger in downstream areas.
\end{abstract}

Key words: Hydro-acoustic / Vertical sounding / Split-beam / Fish / Estuary / Gambia / West Africa

Résumé - Variabilité spatio-temporelle des peuplements de poissons de l'estuaire de la Gambie (Afrique de l'Ouest) échantillonnés par deux méthodes hydroacoustiques verticales : échantillonnage mobile et ancré. L'estuaire de la Gambie est l'un des derniers estuaires d'Afrique de l'Ouest à ne pas avoir subi de perturbations environnementales et anthropiques fortes. Afin de décrire la variabilité spatio-temporelle des biomasses de poissons dans cet estuaire et l'évolution saisonnière des classes de taille, cinq campagnes de recherche ont été menées à des saisons hydrologiques et météorologiques caractéristiques. Les peuplements de poissons ont été échantillonnés par des méthodes hydroacoustiques en utilisant deux types de protocoles différents en émission verticale : en parcours mobiles (transects en zigzag) dans le fleuve et en stations ancrées. Les deux méthodes d'échantillonnage ont fourni une image similaire des peuplements de poissons en terme de biomasse et de distribution d'indices de réflexion. De fortes agrégations ont été détectées dans la zone la plus marine durant la saison humide, et la biomasse de poissons a augmenté pendant la saison sèche dans la zone la plus amont. Les poissons étaient plus petits au début de la saison humide et toujours plus gros dans les zones en aval.

\section{Introduction}

The Gambia Estuary is one of the last aquatic ecosystems of West Africa that has not yet been affected by strong environmental changes and human disturbances. A description of its environmental and biological characteristics is thus of major interest for its sustainable use and conservation. In particular, as the Gambia Estuary plays a considerable role in the Gambian fisheries economy, information on the fish

\footnotetext{
a Corresponding author: guillard@thonon.inra.fr
}

resources is needed to assess its current state, its functioning and to compare it with other neighbouring estuaries, such as the Sine-Saloum (Senegal), that is subjected to different temporal changes.

In large rivers and estuaries, the fish biomass is difficult to estimate (Cowx 1996), since most of the standard sampling methods are difficult to implement and may be limited to certain biotopes (Harvey and Cowx 1996). Although acoustic methods have been used for studying fish populations for several decades (MacLennan and Simmonds 1992), it is only in the last ten years that environments such as 
estuaries, large rivers and streams have been studied by these methods (Duncan et al. 1998; Thorne 1998; Mulligan 2000; Trevorrow et al. 2000). The miniaturisation of the data capture systems and the improved performance of sensors, in particular the improvement of the signal-to-noise ratio, related to the development of electronics, have made it possible to use them in shallow waters. Several recent studies using these methods have been conducted in temperate areas (Guillard et al. 1994; Hughes 1998; Kubecka and Duncan 1998; Kubecka and Wittingerova 1998; Lyons 1998; Kubecka et al. 2000; Frear 2002; Lilja et al. 2003), but there have been few studies in tropical estuaries (Guillard 1998; Krumme and Saint-Paul 2003). Acoustic methods can be used to describe the fish biomass and size class distributions at large spatial and temporal scales, without disturbing the environment or the fish fauna (Brandt 1996). The comprehensive approach consisting of estimating the total biomass, without taxonomic distinction, is necessary for a better understanding of how aquatic ecosystems function and how they evolve with time (Debruyn et al. 2002). In particular, the spatial distribution (Belliard et al. 1997) and temporal changes (Cottingham et al. 2001) in the mean biomass of the fish population and size distributions, which reflect changes in environmental conditions, can be studied.

This paper describes the results of five surveys conducted at different hydrological seasons in the Gambia Estuary. The purposes of this study were (1) to compare the two hydroacoustic protocols used: moored stations and mobile sampling (2) to investigate spatial and temporal distributions in the biomass of the fish assemblages and target strength distributions, in order to determine if there was a longitudinal gradient of biomass and/or fish size in the Gambia Estuary.

This article is part of a series describing the fish and fishing in the Gambia Estuary and its environment. It complements studies of fish assemblages using purse seine (Albaret et al. 2004) and fyke net sampling (Vidy et al. 2004), as well as a description of fishing activities (Laë et al. 2004).

\section{Material and methods}

\subsection{Study area and sampling protocols}

The Gambia River originates in the Fouta Djalon plateau of northern Guinea and flows $1200 \mathrm{~km}$ through southern Senegal and Gambia to the Atlantic Ocean. The total area of the river basin is $78000 \mathrm{~km}^{2}$ (Lesack 1986). The lower Gambia encompassing the whole Gambian part of the river has a virtually zero drainage gradient over the last $500 \mathrm{~km}$. Tidal effects are perceptible up to the Senegal - Gambia border, but according to Daget (1960), true brackish waters are located only in the last $180 \mathrm{~km}$ where tidal flood plains of mangrove swamps are found. Rains occur from June to October with the greatest amount in August. Peak discharge occurs in early to mid September, the rise and fall of discharge is rapid, and it is almost zero from December to the beginning of July (Lesack et al. 1984). The Gambia Estuary is well mixed by currents and the wind and has a longitudinal salinity gradient that varies according to the hydrological seasons. The maximum depth of the estuary in the lower part is greater than $25 \mathrm{~m}$ and exceeds $10 \mathrm{~m}$ in the upper part.
The sampling was based on the zonation produced by Dorr et al. (1985). The entire sampled area corresponded to only three of the five zones defined: the lower and upper estuary and a part of the lower river zone (freshwater with a tidal influence). The surveys took place at five different hydrological seasons in order to cover all types of environmental situations (Table 1). The first exploratory survey in November 2000 (g1) was used to test the sampling strategies, in order to standardize the protocols for the following sampling surveys. Then the surveys are described in seasonal order, from the beginning of the cool season (lowest salinity, September), to the end of the dry and warm season (highest salinity, June), and disregarding variability between years: g3, g1, g4, g5, g2 (Table 1). This work was focused on the fish assemblages of the main channel of the Gambia Estuary, except for one side branch, the Bintang "bolong". The data were grouped into three zones, of about the same length of $60 \mathrm{~km}$ (Fig. 1), in order to distinguish the major trends and eliminate local variability:

- The lower zone up to Mootah Point (Z1), with salinity always above 15 , under direct marine influence.

- The intermediate zone from Mootah Point to Krul Point (Z2).

- The zone upstream of Krul Point (Z3), with the widest salinity range and therefore the greatest spatial and seasonal variations: from 0 to 25 at the lower end of the zone in the dry season.

Hydro-acoustic sampling was conducted during day time, simultaneously with purse seine surveys performed from a second boat (Albaret et al. 2004). Fishing stations were distributed throughout the whole estuary and were located in as many types of environments as possible, right and left bank, nearshore and in the middle of the channel, at various depths (up to $20 \mathrm{~m}$ ), with or without nearby mangroves, etc. Two types of vertical acoustic acquisition were used: the first was a classical mobile sampling, consisting of 30 min zigzag transect at low speed (mean speed of $6 \mathrm{~km} \mathrm{~h}^{-1}$ ) in the estuary, i.e. about $3 \mathrm{~km}$ between two fishing stations, sampling the various biotopes encountered (channel, near left banks, near right banks) (Fig. 1, Table 1). The second acoustic protocol was echosounding vertically from a moored position for $30 \mathrm{~min}$ (Fig. 1, Table 1), at the same sites where hydrological variables were measured from the main boat which was very stable. At the same time, fishing operations were conducted nearby in an equivalent zone in terms of depth and distance from the shore. An instantaneous index of fish biomass and the target strength distribution at each station were therefore obtained.

\subsection{Equipment}

The equipment used was an echosounder SIMRAD EY500, split-beam, $120 \mathrm{kHz}$ frequency system, fixed to the side of the boat and vertically oriented. The transducer is circular, with a total beam angle of $7.1^{\circ}$ at $-3 \mathrm{~dB}$; the pulse length is $0.3 \mathrm{~ms}$, with a pulse repetition rate of about 8 emissions per second. The discrimination characteristics of the individual targets are: minimum and maximum returned pulse width 0.6 to 1.8 fold the transmitted pulse duration, maximum gain compensation $6 \mathrm{~dB}$ and a maximum phase deviation of 3 phase 


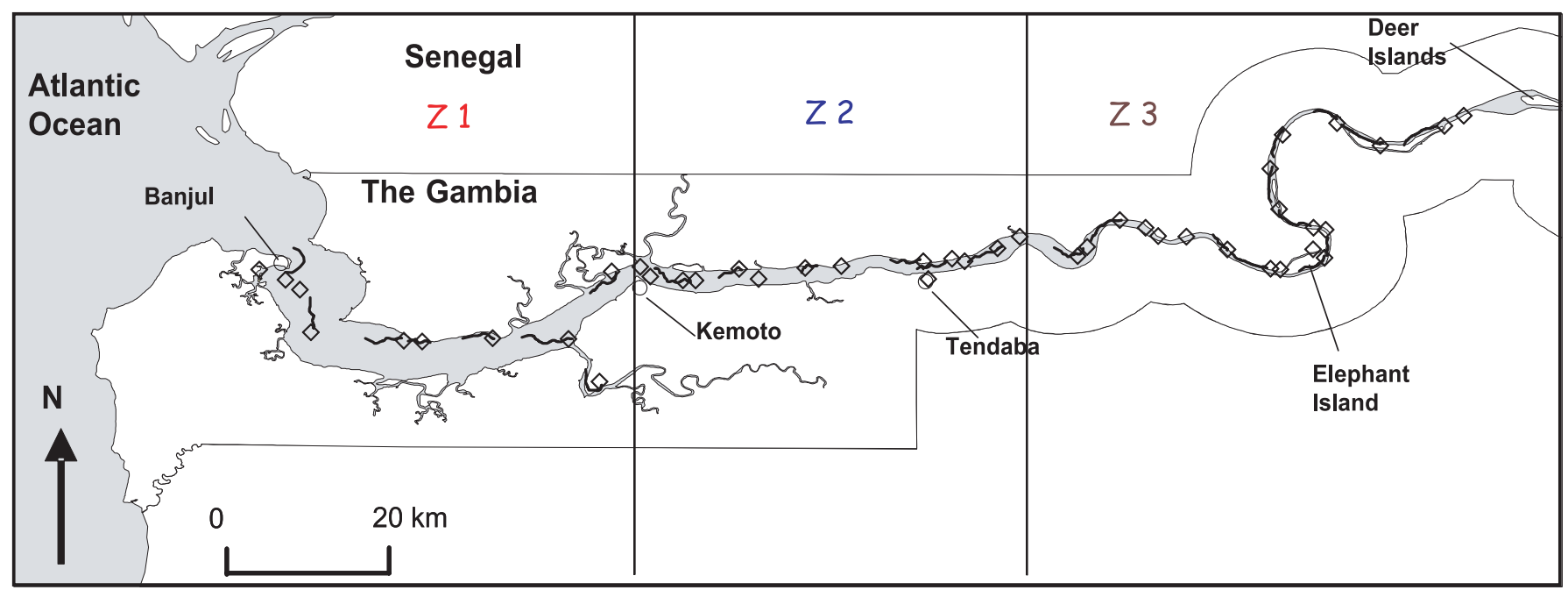

Fig. 1. The Gambia Estuary with geographical positions of the moored stations (white lozenge) and transects from mobile sampling (black lines).

Table 1. Summary of surveys.

\begin{tabular}{llllc}
\hline Survey code & Dates & Season & No. transects & $\begin{array}{c}\text { No. acoustic stations } \\
\text { associated with fishing stations }\end{array}$ \\
\hline g1 & 23 Nov.-4 Dec. 2000 & $\begin{array}{l}\text { End of wet season, } \\
\text { lowest theoretical salinity }\end{array}$ & 38 & $0 / 39$ \\
g2 & 02-12 June 2001 & $\begin{array}{l}\text { End of warm and dry season, } \\
\text { highest theoretical salinity }\end{array}$ & 18 used / 25 & $22 / 43$ \\
g3 & 16-26 Sep. 2001 & Wet and flood season & 25 & $44 / 46$ \\
g4 & 3-13 Dec. 2001 & Start of dry and cool season & 26 & $44 / 46$ \\
g5 & 15-24 April 2002 & Start of dry and warm season & 27 & $44 / 46$ \\
\hline
\end{tabular}

steps (Jørgensen and Olsen 2002). Noise thresholds were set at $-60 \mathrm{~dB}$ for target strength "TS" in $40 \log R$ time-variedgain function, and at $-55 \mathrm{~dB}$ for echointegration in $20 \log R$ time-varied-gain function data. An IBM-PC compatible computer controlled the echosounder, which was connected to a GPS, data were stored on the hard disk and regularly saved on CD-ROM; the whole system being powered by a $12 \mathrm{~V}$ battery. Calibrations were carried out before the surveys in an experimental tank (IFREMER, Brest, France), and repeated onboard during each series of acoustic surveys, using a copper calibration sphere and following the standard protocol recommended by Foote et al. (1987). At each hydrological station the water salinity and temperature were measured using a YSI probe (Albaret et al. 2004) and measurements were used to correct the echosounder's parameters in relation to the absorption coefficient $(\alpha)$ and the speed of the sound propagation in the water.

\subsection{Post processing and data analysis}

Data were analysed by the EP500 software from SIMRAD, to calculate the fish biomass, i.e. the area backscattering coefficient $\mathrm{Sa}\left(\mathrm{m}^{2} \mathrm{~m}^{-2}\right)$ (MacLennan et al. 2002). The target strength distributions were computed by the EP500 SIMRAD "tracking menu" on tracked fish, with the default parameters. For each elementary sampling unit - transect and 30 min moored station - a biomass in Sa units, a TS distribution, and a median TS were obtained.

\subsection{Statistical analyses}

Values of biomass obtained by both acoustic protocols were compared using Kruskal-Wallis non parametric test (Sprent 1992). This test was applied to the comparison between zones for each survey and to the comparison between surveys for each zone. A non parametric Smirnov test (Sprent 1992) was used to compare the TS distributions obtained by the two sampling protocols, for each zone and for each survey.

\section{Results}

In this part, we first present the results on the fish biomass detected, then the TS distributions, and finally a comparison between the two acoustic sampling strategies. In the Gambia Estuary, two types of fish echoes were encountered (Fig. 2), individual targets and schools, but the latter only occurred in the lower estuary. 


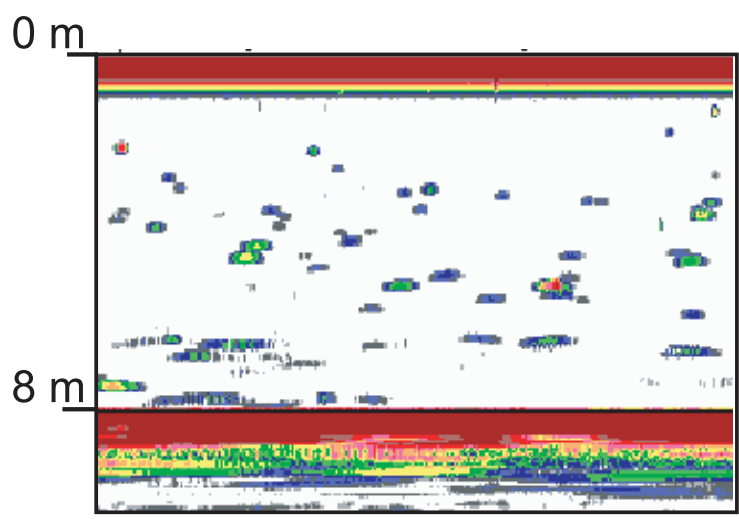

a
$0 \mathrm{~m}$

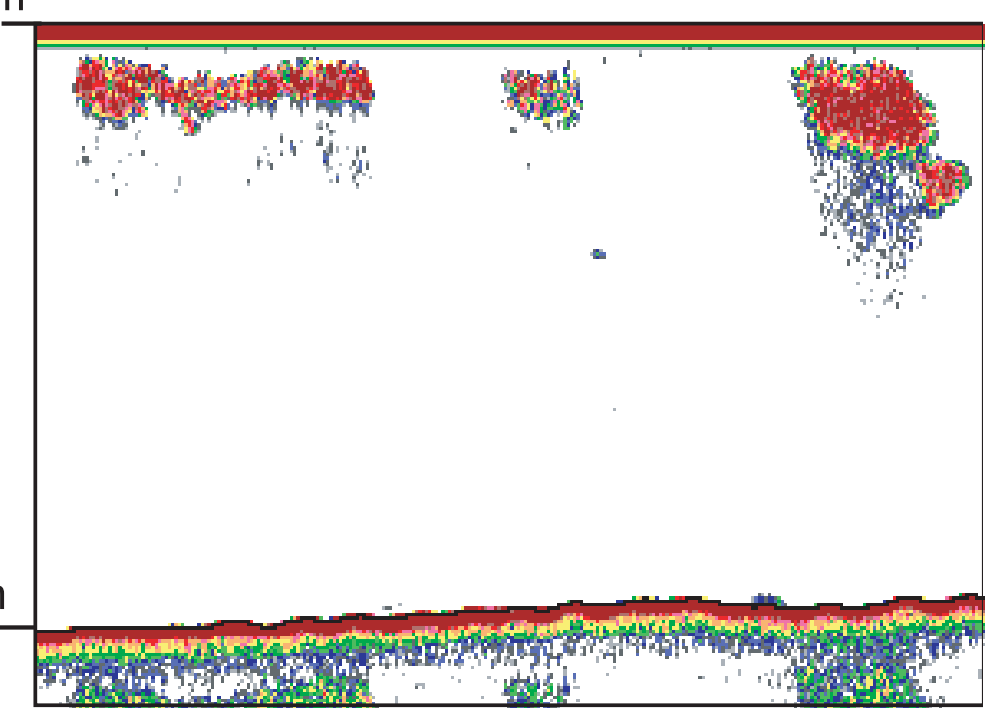

b

Fig. 2. Examples of echograms showing the two types of echoes detected: individual targets (a), fish schools (b).

\subsection{Biomass detected}

\subsubsection{Mobile sampling}

The Sa value obtained for each transect are shown for the five sampling surveys (Fig. 3a). Large variations at a seasonal scale were observed, with low values of biomass during the wet season (September), higher values in the most marine zone at the end of the wet season (November and December), and finally high values of biomass in the most upstream zone in the period of highest salinity (April and June). The KruskalWallis test applied to the comparison between zones showed for each survey, except in April, a significant heterogeneity between zones at the probability level of 0.05 (Table 2). The comparison between surveys also showed significant differences, except for the intermediate zone $\mathrm{Z} 2$ where the biomass was stable. There were large variations in the downstream zone $\mathrm{Z} 1$ caused by the detection of schools, which were mainly observed during the wet season. In the upstream zone, the biomass increased as the salinity became higher through the dry season.

\subsubsection{Moored positions}

The maps of biomass detected at the moored stations (Fig. 3b) share characteristics with the mobile sampling, such as the high biomass in the dry season in the upstream zone, and heterogeneity between zones. In contrast, the very high values of biomass observed in the lowest zone no longer appeared. The Kruskal-Wallis tests between zones for each survey (Table 2) were not significant in September and April and only just significant in June and December. As for the mobile sampling data, very significant differences between surveys were observed in the upstream zone $\mathrm{Z3}$, with higher values of biomass observed during the dry season (Table 3 ). The test was not significant for the intermediate zone, neither for the downstream zone, due to the non-detection of the large schools detected by mobile sampling.

\subsection{Target Strength distributions}

TS distributions of tracked fish were computed for each elementary sampling unit, transect and moored position (Fig. 5), with all the tracked fish in the area, with a minimum number of 512 data points to a maximum of 9296 . The distributions for the two kinds of samples, for each zone, are identical: for all the surveys, Smirnov test was significant, $p<0.05$. The median values of TS were smaller at the beginning of the season than at the end, in all areas. Median TS values were always larger in downstream areas, a difference of about $4 \mathrm{~dB}$ (Fig. 6). In the upstream area, there were large variations of more than $10 \mathrm{~dB}$ with a smaller TS during the wet season.

\subsection{Comparison of mobile surveys and moored stations (Fig. 7)}

The median values of fish biomass in Sa units for each zone obtained by the two sampling acoustic methods (Table 3 ), mobile and moored sampling were significantly correlated ( $n=11, r=0.91, p<0.01)$, with the exception of one point (Fig. 7). This point was the median of the samples from the downstream area, Zone 1 in December, a season during which many large schools were detected by mobile sampling but not in the moored acoustic stations. In the same way the median value of TS obtained for the mobile and fixed sampling were significantly correlated $(n=12, r=0.87, p<0.01)$. The two sampling methods produced a similar image of the fish assemblages in terms of the distribution of total biomass and TS. 

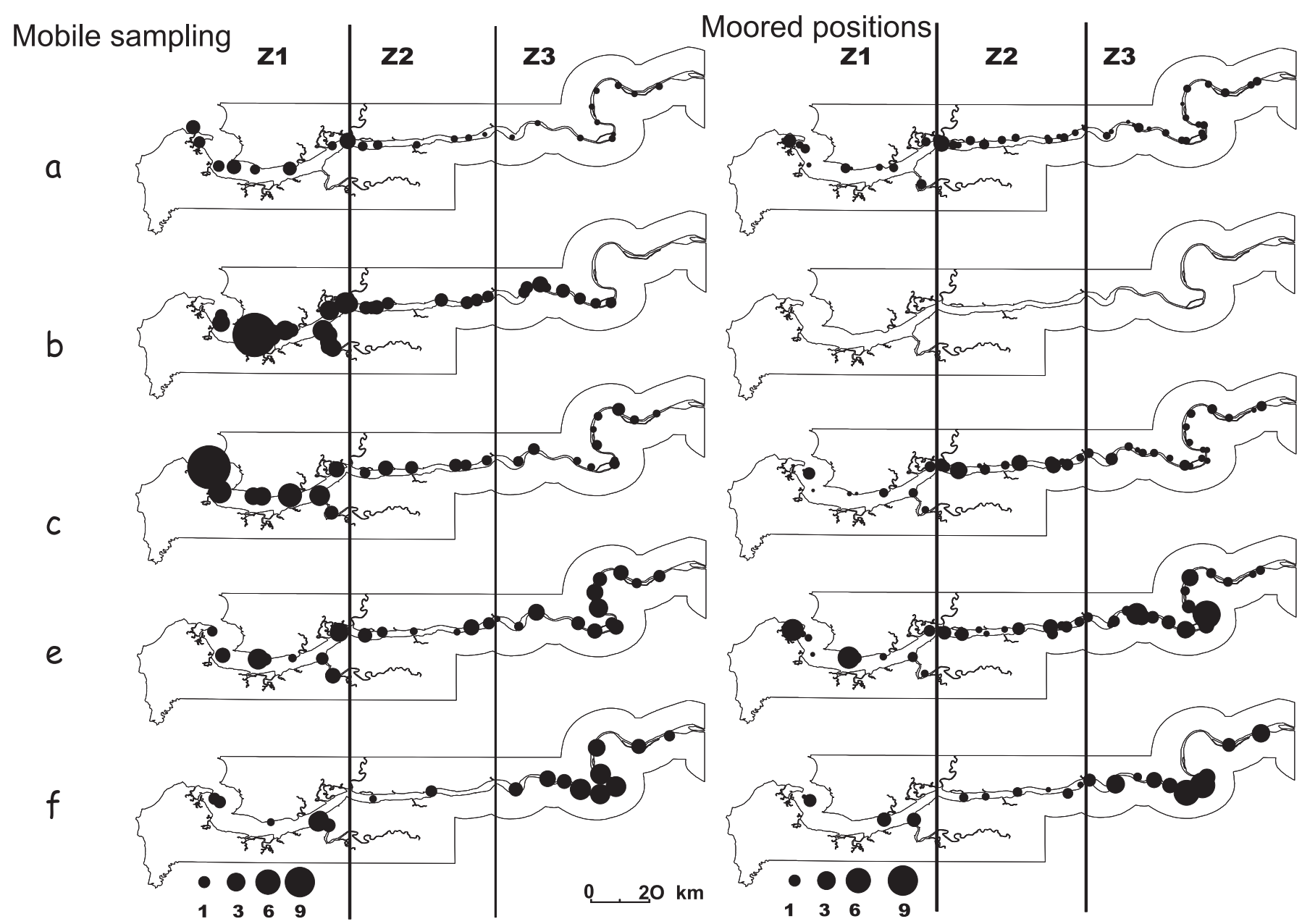

Fig. 3. Biomass detected (area backscattering coefficient $\left(\mathrm{m}^{2} \mathrm{~m}^{-2}\right)$ during the mobile sampling and the moored stations conducted in the different hydrological seasons; (a) September 2001, (b) November 2000, (c) December 2001, (d) April 2002, (e) June 2001.

\section{Discussion}

The great depth of the Gambia Estuary - more than $10 \mathrm{~m}$ - allowed us to use vertical acoustic detection, instead of horizontal detection that is often used in this type of environment (Hughes 1998; Kubecka and Duncan 1998; Lyons 1998) and recommended in shallow water environments (Kubecka and Wittingerova 1998; Knudsen and Sægrov 2002). Horizontal detection is known to be difficult to use under windy conditions (Mouse and Kemper 1996; Knudsen and Sægrov 2002) that occur very often in this environment. Even though the sampled volume is greater by horizontal sounding, it is still not exhaustive. Moreover, TS distributions are awkward to compute without knowledge of fish orientations in the acoustic beams, swimming motions, that are inevitably variable in zigzag transects. As opposed to horizontal acoustic sampling, vertical samples produced good quality data: reflections on fish were from a dorsal view, background noise was low, there was no parasite echo from the surface or bottom, vertical beaming provided a good image of fish distributions in the water column, specifically when pelagic and epibenthic fish are dominant in the population as it is the case in the Gambia Estuary (Albaret 1999). As pointed by Krumme and St Paul (2003) experiments using vertical transducer orientation could be worthwhile alternatives.

The use of acoustic methods in estuarine and riverine environments (Thorne 1998; Mulligan 2000), particularly those that are sufficiently deep, is a complement to traditional sampling techniques (Frear 2002). These methods give a quick estimate of the existing biomass and of its temporal changes in relation to the highly variable environmental factors in tropical estuaries. Furthermore, split-beam echosounders provide an estimate of TS distributions, so that spatial and temporal changes in the size of targets can be monitored. Seventy fish species, belonging to 32 families, have been recorded by Albaret et al. (2004) in the Gambia Estuary. The nine most abundant species account for $88.3 \%$ of the total fish sample biomass. All of them have a well developed swimbladder. This is particularly the case of the sciaenid Pseudotolithus elongatus, the most abundant (almost $48.5 \%$ ) and frequent species $(96.6 \%)$. The most abundant species without a swimbladder is the tongue sole (Cynoglossus senegalensis) representing only $1.2 \%$ of total biomass caught. Despite the high diversity of fish species, the absence of data on the relation between fish size and TS for each species, and the TS variability (MacLennan and Simmonds 1992), TS distributions can 
Table 2. Results of the Kruskal-Wallis tests applied to the average biomass values obtained by mobile sampling (a) and moored stations (b). Tests are computed separately between zones for each survey and for comparison of surveys, tests are computed for each zone. $N$ : number of sampling units. $H$ : Kruskal-Wallis statistics (corrected in case of tied values). $p$ value: probability level. $\left({ }^{* *}\right.$ : very significant difference, $p<0.1$, *: significant difference, $p<0.5$, NS: non significant).

\begin{tabular}{lccc}
\hline & $N$ & $H$ & $p$ value \\
\hline Between zones & & & \\
g3 (a) & 25 & 14.45 & $0.001\left(^{* *}\right)$ \\
g1 (a) & 38 & 13.25 & $0.001\left(^{* *}\right)$ \\
g4 (a) & 26 & 18.83 & $<0.0001\left(^{* *}\right)$ \\
g5 (a) & 27 & 1.91 & $0.385(\mathrm{NS})$ \\
g2 (a) & 18 & 6.34 & $0.042\left(^{*}\right)$ \\
& & & \\
Between surveys & & & \\
Z1 (a) & 49 & 15.02 & $0.004\left(^{* *}\right)$ \\
Z2 (a) & 31 & 7.17 & $0.127(\mathrm{NS})$ \\
Z3 (a) & 54 & 37.82 & $<0.0001\left(^{* *}\right)$ \\
Between zones & & & \\
g3 (b) & 44 & 4.58 & $0.101(\mathrm{NS})$ \\
g1 (b) & - & - & - \\
g4 (b) & 44 & 9.32 & $0.009\left(^{* *}\right)$ \\
g5 (b) & 44 & 4.63 & $0.098(\mathrm{NS})$ \\
g2 (b) & 22 & 8.73 & $0.012\left({ }^{*}\right)$ \\
Between surveys & & & \\
Z1 (b) & 34 & 5.30 & $0.151(\mathrm{NS})$ \\
Z2 (b) & 49 & 4.55 & $0.208(\mathrm{NS})$ \\
Z3 (b) & 71 & 38.73 & $<0.0001\left(^{* *}\right)$ \\
\hline
\end{tabular}

Table 3. Median biomass values detected, area backscattering coefficient $\left(\mathrm{m}^{2} \mathrm{~m}^{-2}\right)$, per transect (mobile survey) and per moored station in the three zones.

\begin{tabular}{lccc}
\hline Median (No. ESDU) & Z1 & Z2 & Z3 \\
\hline Transect & & & \\
g3 & $0.95(7)$ & $0.28(7)$ & $0.15(11)$ \\
g1 & $2.46(20)$ & $1.10(10)$ & $0.98(8)$ \\
g4 & $3.34(8)$ & $1.06(6)$ & $0.45(12)$ \\
g5 & $1.49(8)$ & $0.90(6)$ & $1.56(13)$ \\
g2 & $1.25(6)$ & $0.61(2)$ & $2.45(10)$ \\
\hline Moored station & & & \\
g3 & $0.48(10)$ & $0.36(14)$ & $0.26(20)$ \\
g1 & $*$ & $*$ & $*$ \\
g4 & $0.30(10)$ & $0.68(14)$ & $0.17(20)$ \\
g5 & $1.14(10)$ & $0.60(14)$ & $0.48(20)$ \\
g2 & $1.38(4)$ & $0.49(7)$ & $2.44(11)$ \\
\hline
\end{tabular}

be roughly compared to size distributions according to Love's equation (Love 1977). As the information on the relations between species and TS was not available for all the targets detected, the Sa values could not be converted into kilograms (MacLennan and Simmonds 1992).

The fish assemblages of the Gambia Estuary change in terms of biomass and size distributions from the wet season to the end of the dry season. The lowest biomass was detected in the wet season when the salinity was lowest, in all the zones
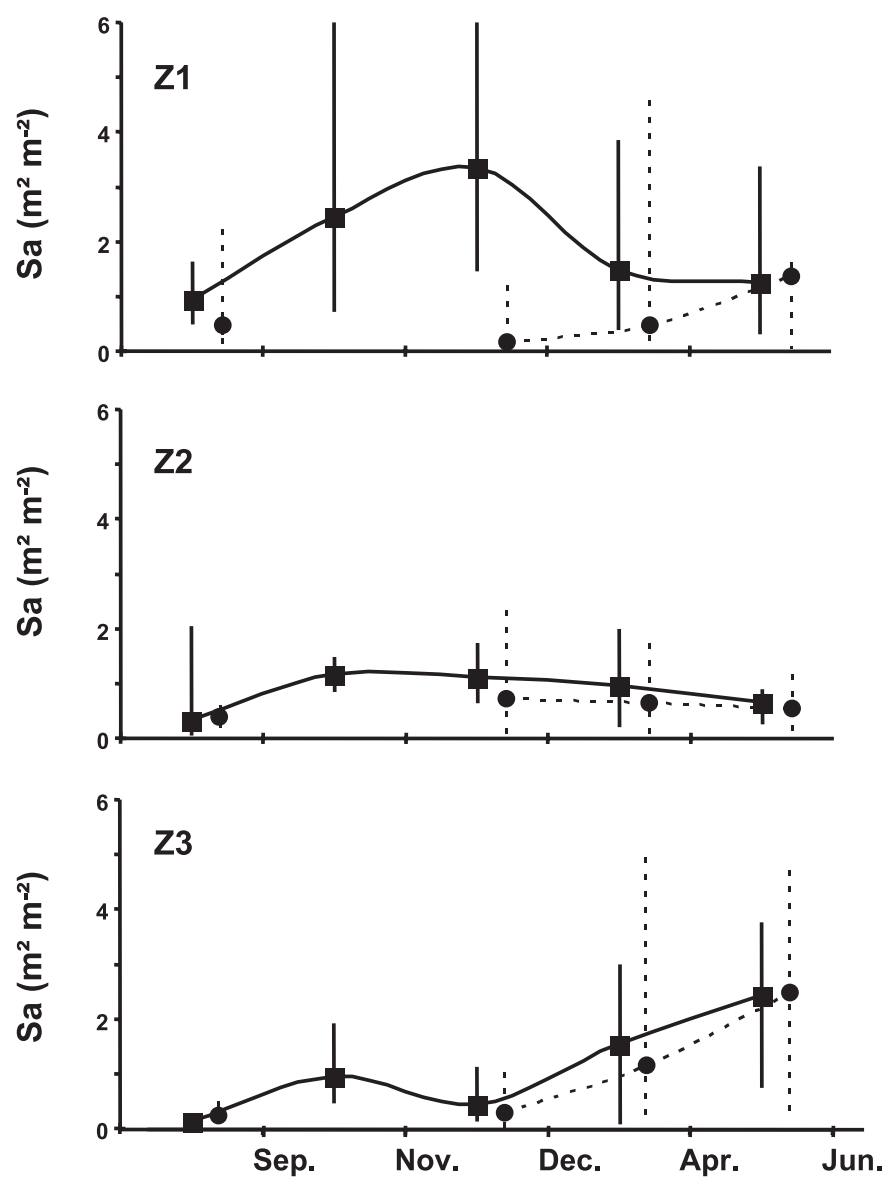

Fig. 4. Median biomass (area backscattering coefficient $\left(\mathrm{m}^{2} \mathrm{~m}^{-2}\right)$ detected from September to June for area Z1, Z2 and Z3. The vertical lines (straight line for mobile sampling, dotted line for moored stations) indicate the maximum values and the minimum values for each zone, the square the median for mobile surveys and the circle, the median for moored stations.

of the estuary. High concentrations of fish schools (Ethmalosa fimbriata, Sardinella maderensis) (Albaret et al. 2004) were only recorded at the end of the wet season, and only close to the sea. Fish abundance in the most marine area increased on average roughly three times at the end of the wet season compared to the other seasons. In contrast, high values of biomass were recorded furthest upstream, with a progressive increase in biomass, more than 5 times, as the salinity became higher through the dry season. Fish size distributions at the beginning of the season (September) pointed to the presence of small fish, and the median TS then increased through the season suggesting the presence of larger fish. In the downstream areas fish were always larger than in the other areas. The important variation of TS in the upstream zones between seasons, with an increase of $10 \mathrm{~dB}$ suggested the role of theses areas as a nursery. These results are in agreement with the general trends drawn from the study conducted simultaneously by the purse seine sampling (Albaret et al. 2004). The lowest fish biomass was also noted in September and November during the wet season. During the dry season many marine and marine-estuarine species enter the estuary. These species 


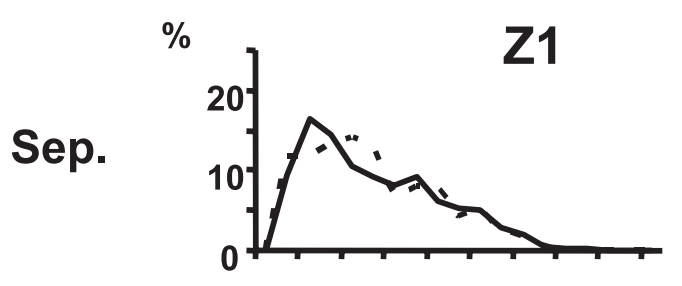

$\%$

Nov.

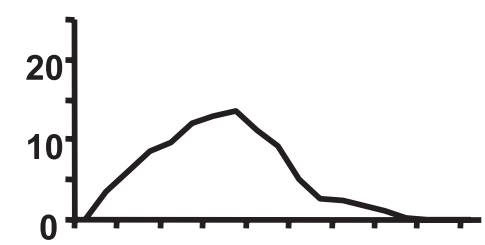

$\%$

Dec.

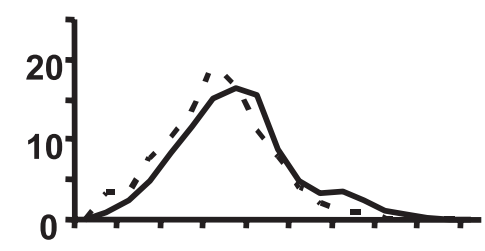

$\%$

Apr.

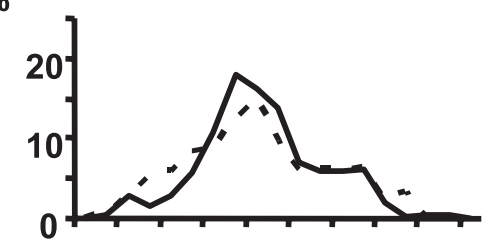

$\%$

Jun.

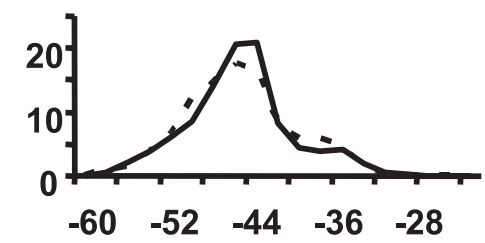

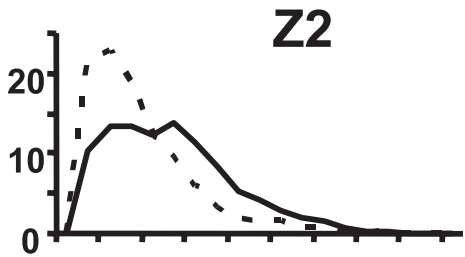
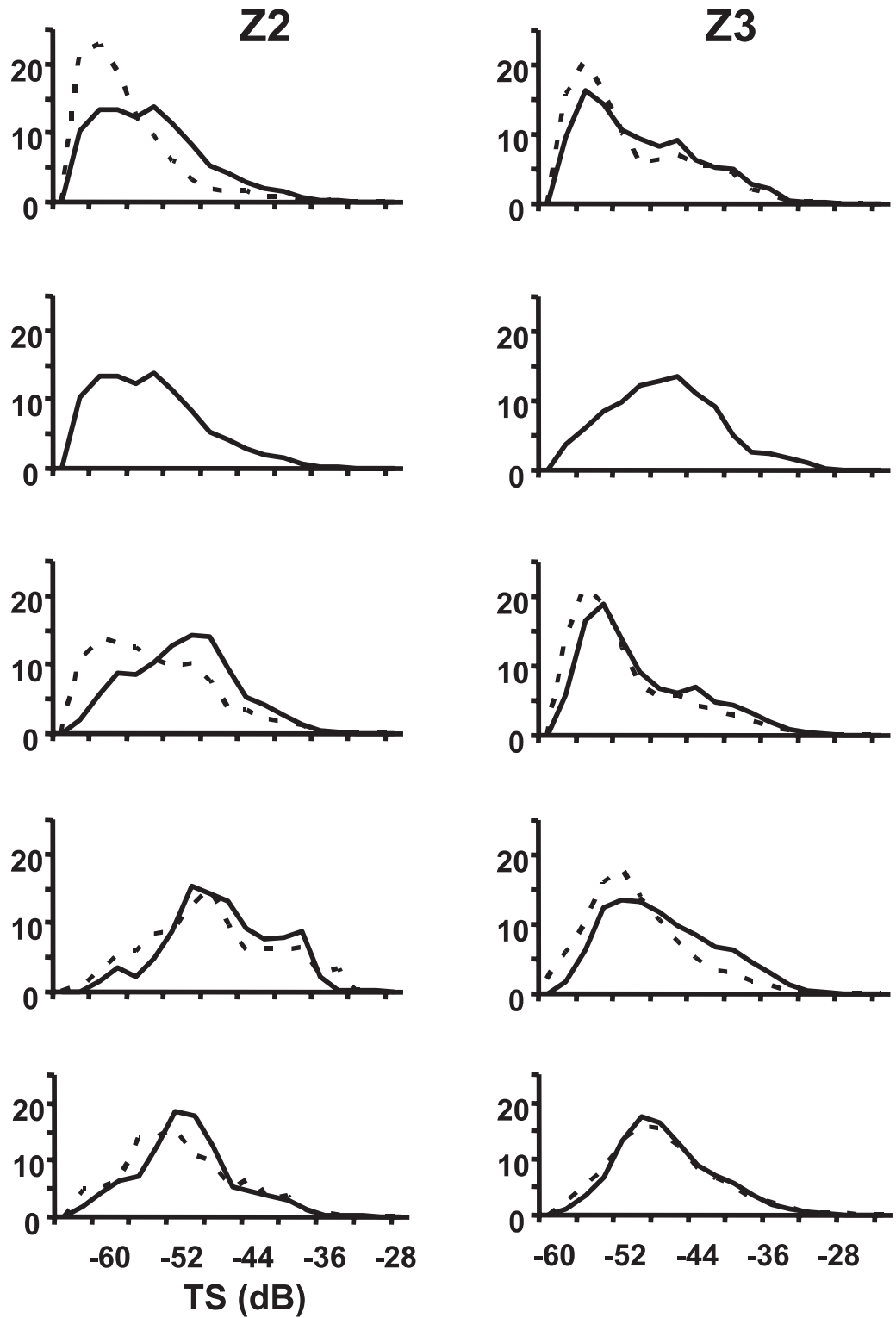

Fig. 5. Target strength distributions of tracked fish by zone, for all the surveys, for transects (straight line) and moored stations (dotted line).

migrate upstream and colonize the whole estuary including the upper reaches (Albaret et al. 2004). Some inland water species tolerant of low salinity, such as Synodontis gambiensis, Synodontis batensoda, Schilbe mystus, and the catfishes Chrysichthys nigrodigitatus and Chrysichthys maurus, contributed to the high values of biomass detected by acoustic methods during the dry season. We emphasize the obvious interest of the acoustic methods, with thier reduced cost, except for the initial outlay on equipment, whereas the use of traditional techniques is often expensive in time and manpower (Schramm et al. 2001). Hydroacoustic sampling is highly suitable for monitoring the fish assemblages of marine or estuarine protected areas where fish sampling is very difficult to complete.

The two complementary approaches used, transects and vertical observations from a moored position, gave a similar image of the fish population in terms of mean biomass and
TS distributions. The first method is more integrative because various biotopes are sampled and the water volume sampled is greater, whereas the second one could not integrated local heterogeneity. The two approaches provided conflicting results in areas where schools of fish occurred, as these were very rarely detected at a moored station. In all cases, acoustic data acquisition was conducted from a boat and there are certainly problems of fish behaviour including avoidance (Fréon and Misund 1999) and attraction phenomena (Fréon and Dagorn 2000). It is impossible to determine the effects of such behaviour without specific experimentation that would require the use of additional techniques such as multibeam sonar (Gerlotto et al. 1999; Brehmer et al. 2003) and underwater video. Nevertheless, major attraction or avoidance seems unlikely in an estuary for the short periods of mooring of about half an hour that were used in our study, and with a very weak transparency (Albaret et al. 2004). 

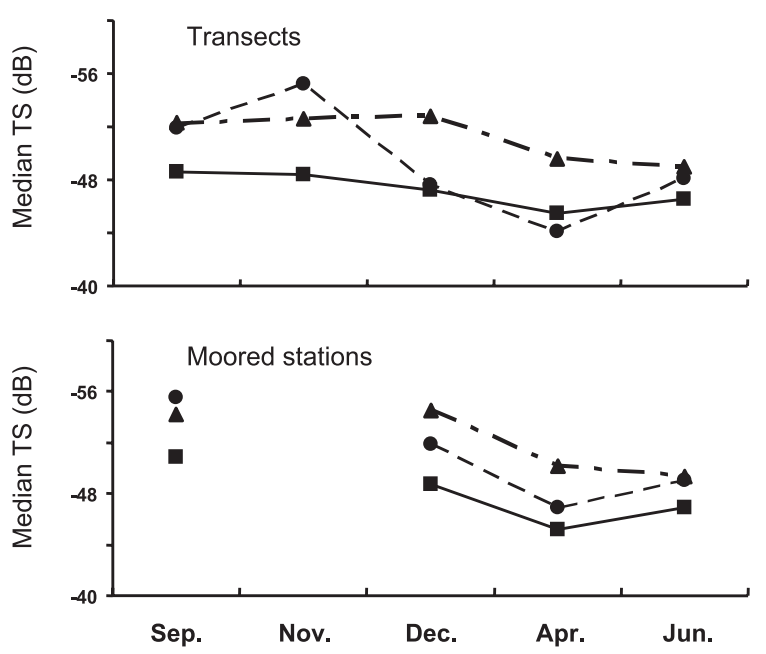

Fig. 6. Median TS (dB) detected per zone during the mobile surveys and the moored stations throughout seasons $(\bullet \mathrm{Z} 1, \bullet \mathrm{Z} 2, \mathbf{\Delta} \mathrm{Z} 3)$.
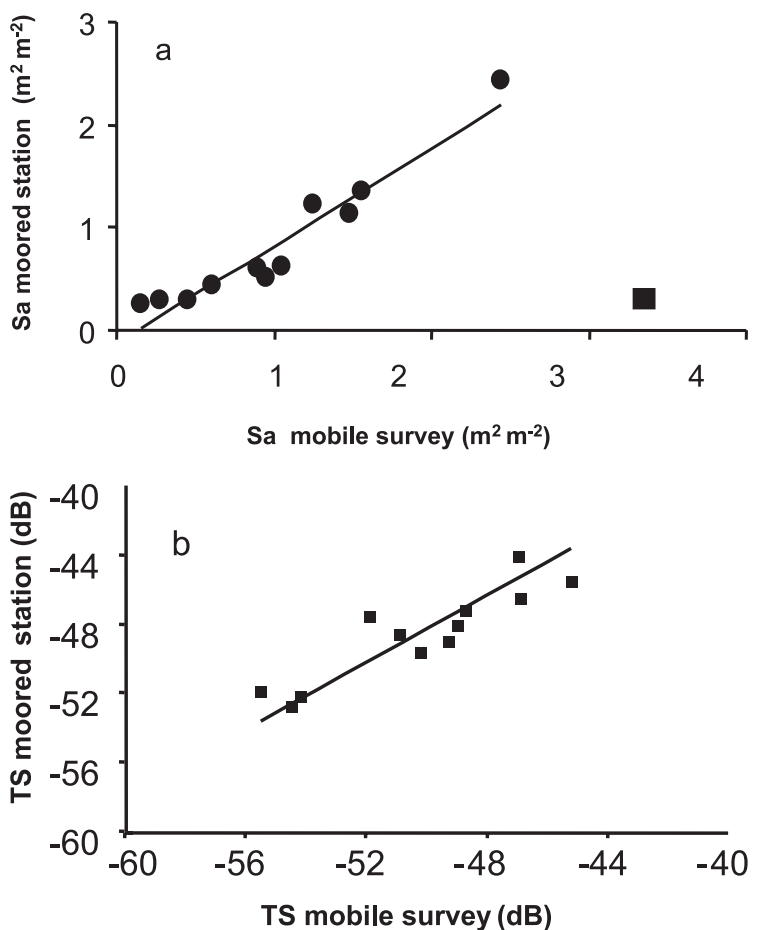

Fig. 7. (a) Correlation between the median biomass (area backscattering coefficient, $\mathrm{m}^{2} \mathrm{~m}^{-2}$ ) detected per mobile survey and per moored station, excluding one point ( $\mathbf{a})$; (b) Correlation between the median TS detected per mobile survey and per moored station.

\section{Conclusion}

These two non-intrusive protocols produce a similar image of the fish assemblages in biomass and size distributions. Hydro-acoustic methods permit us to monitor the seasonal and spatial changes of the fish assemblages in this tropical estuary throughout seasons and space. Particularly we emphasize the high biomass detected in the marine part of the estuary at the end of the wet season and the increases of fish biomass in the upstream zone during the dry season.
Acknowledgements. We would like to thank all the Gambian and Senegalese fishermen for the experimental fishing surveys that they conducted, including the crew of the Diassanga, the IRD Dakar research vessel, François Sanseo and Cesar Tendeng, plus our Gambian colleagues F.S. Darboe and M. Suwareh of the Gambian Fisheries Department. The authors wish to thank particularly the two anonymous referees for their help and P. Brehmer and P. Roux for their helpful hints.

\section{References}

Albaret J.J., 1999, Les peuplements des estuaires et des lagunes. In: Lévêque C., Paugy D. (Eds.) Les poissons des eaux continentales africaines : diversité, écologie, utilisation par l'homme. IRD, Paris, pp. 325-349.

Albaret J.J., Simier M., Darboe F.S., Ecoutin J.M., Raffray J., Tito de Morais L., 2004, Fish diversity and distribution in the Gambia Estuary, West Africa, in relation to environmental variables. Aquat. Living Resour. 17, 35-46.

Belliard J., Boët P., Tales E., 1997, Regional and longitudinal patterns of fish community structure in the Seine River basin, France. Environ. Biol. Fish. 50, 133-147.

Borgmann U., 1987, Models on the slope of, and biomass flow up, the biomass spectrum. Can. J. Fish. Aquat. Sci. 44, 136-140.

Brandt S.B., 1996, Acoustic assessment of fish abundance and distribution. In: Murphy B.R. Willis D.W. (Eds.) Fisheries Techniques, $2^{\text {nd }}$ edition. Am. Fish. Soc. pp. 385-432.

Brehmer P., Gerlotto F., Guillard J., Sanguinède F., Guennégan Y., Buestel D., 2003, New applications of under-acoustics methods for monitoring shallow water aquatic ecosystems: the case of mussel culture grounds in open sea. Aquat. Living Resour. 16, 333-338.

Cottingham K.L., Brown B.L., Lennon J.T., 2001, Biodiversity may regulate the temporal variability of ecological systems. Ecol. Lett. 4, 72-85.

Cowx I.G., 1996, Stock assessment in inland fisheries. Fishing News Books, Blackwell Sci. Publ., London.

Daget J., 1960, La faune ichtyologique du bassin de la Gambie. Bull. Inst. Fr. Afr. N., 22, 611-619.

Debruyn A.M.H., Marcogliese D.J., Rasmussen J.B., 2002, Regional analysis of body size and population density in stream fish assemblages: testing predictions of the energetic equivalence rule. Can. J. Fish. Aquat. Sci. 59, 819-828.

Dorr J.A.III, Schneeberger P.J., Tin H.T., Flath L.E., 1985, Studies on adult, juvenile and larval fishes of the Gambia river, West Africa, 1983-1984, Report n 11, Great Lakes and Marine Waters Center international programs, The University of Michigan, Ann Arbor, Michigan.

Duncan A., Butterworth A.J., Gerlotto F., Kubecka J., 1998, Editorial. Fish. Res. 35, 1-3.

Foote K.G., Knudsen H., Vestnes G. 1987, Calibration of acoustic instruments for fish density estimation: a practical guide. ICES Coop. Res. Rep. 144.

Frear P.A., 2002, Hydroacoustic target strength validation using angling creel census data. Fish. Manage. Ecol. 9, 343-350.

Fréon P., Misund O.A., 1999, Dynamics of pelagic fish distribution and behaviour: effects on fisheries and stock assessment. Fishing News Books, Blackwell Science, Oxford.

Fréon P, Dagorn L., 2000, Review of fish associative behaviour: toward a generalisation of the meeting point hypothesis. Rev. Fish Biol. Fish. 10, 183-207. 
Gerlotto F., Soria M., Fréon P., 1999, From two dimensions to three: the use of multibeam sonar for a new approach in fisheries acoustics. Can. J. Fish. Aquat. Sci. 56, 6-12.

Guillard J., 1998, Daily migration cycles of fish populations in a tropical estuary (Sine-Saloum, Senegal) using a horizontal-directed split-beam transducer and multibeam sonar. Fish. Res. 35, 21-29.

Guillard J., Boet P., Gerdeaux D, Roux P., 1994, Application of mobile acoustic techniques fish survey in shallow waters: the river Seine. Regul. Rivers 9, 121-126.

Harvey J., Cowx I.G., 1996, Electric fishing for assessment of fish stocks in large rivers. In: Cowx I.G. (Ed.) Stock Assessment in Inland Fisheries. Fishing News Books, Blackwell Science, Oxford, pp. 11-26.

Hughes S., 1998, A mobile horizontal hydroacoustic fisheries survey of the River Thames, United Kingdom. Fish. Res. 35, 91-97.

Jorgensen R. Olsen K., 2002, Acoustic target strength of capelin measured by single-target tracking in a controlled cage experiment. ICES J. Mar. Sci. 59, 1081-1085.

Knudsen F.R. Sægrov H., 2002, Benefits from horizontal beaming during acoustic survey: application to three Norwegian lakes. Fish. Res. 56, 205-211.

Krumme U., Saint-Paul U., 2003, Observations of fish migration in a macrotidal mangrove channel in Northern Brazil using a $200 \mathrm{kHz}$ split-beam sounder. Aquat. Living Resour. 16, 175-184.

Kubecka J., Duncan A., 1998, Acoustic size vs. real size relationships for common species of riverine fish. Fish. Res. 35, 115-125.

Kubecka J., Frouzova J., Vilcinskas A., Wolter C., Slavik O., 2000, longitudinal hydroacoustic survey of fish in the Elbe River supplemented by dircet capture. In: Cowx I.G. (Ed.) Stock Assessment in Inland Fisheries. Fishing News Books, Blackwell Science, Oxford, pp. 14-26.

Kubecka J., Wittingerova M., 1998, Horizontal beaming as a crucial component of acoustic fish stock assessment in freshwater reservoirs. Fish. Res. 35, 99-106.

Laë R., Ecoutin J.M., Mendy A., Raffray J., Weigel J.Y., Sadio O., Djobe O., 2004, Effects of a targeted shrimp (Penaeus notialis) exploitation on fish catches in the Gambia estuary. Aquat. Living Resour. 17, 75-85.
Lesack L.F.W., 1986, Estimates of catch and potential yield for riverine artisanal fishery in The Gambia, West Africa. J. Fish Biol. 28, 679-700.

Lesack L.F.W., Hecky R.E., Melack J.M., 1984, Transport of carbon, nitrogen, phosphorus and major solutes in the Gambia River, West Africa. Limnol. Oceanogr. 29, 816-830.

Love R.H., 1977, Target strength of an individual fish at any aspect. J. Acoust. Soc. Am. 72, 1397-1402.

Lilja J., Keskinen T., Marjomäki T.J., Valkeajärvi P., Karjalainen J., 2003, Upstream migration activity of cyprinids and percids in a channel, monitored by a horizontal split-beam echosounder. Aquat. Living Resour. 16, 185-190.

Lyons J., 1998, A hydroacoustic assessment of fish stocks in the River Trent, England. Fish. Res. 35, 83-90.

MacLennan D., Fernandes P.G., Dalen J., 2002, A consistent approach to definitions and symbols in fisheries acoustics. ICES J. Mar. Sci. 59, 365-369.

MacLennan D.N., Simmonds E.J., 1992, Fisheries acoustics, Chapman and Hall, New York.

Mouse P.J., Kemper J., 1996, Applications of a hydroacoustic sampling technique in a large wind-exposed shallow lake. In: Cowx I.G. (Ed.) Stock Assessment in Inland Fisheries. Fishing News Books, Blackwell Science, Oxford, pp. 179-195.

Mulligan T., 2000, Shallow water fisheries sonar: a personal view. Aquat. Living Resour. 13, 269-273.

Schramm H.L., Grado S.C., Pugh L.L., 2001, The costs of sampling fishes in riverine habitats of a large river. Fish. Res. 56, 51-57.

Sprent P., 1992, Pratique des statistiques non paramétriques. INRA Paris.

Thorne D., 1998, Review: experiences with shallow water acoustics. Fish. Res. 35, 137-142.

Trevorrow M., Burczynski J., Kubecka J., 2000, Editorial. Aquat. Living Resour. 13, 267.

Vidy G., Darboe F.S., Mbye E.M., 2004, Juvenile fish assemblages in the creeks of the Gambia estuary. Aquat. Living Resour. 17, 56-64. 